\title{
The Effect of Infill Steel Plate Thickness on the Cycle Behavior of Steel Plate Shear Walls
}

\author{
Amer M. Ibrahim, Huda M. Najem \\ Department of Civil Engineering, College of Engineering, University of Diyala \\ huda.m.najem1992@gmail.com
}

\begin{abstract}
Steel plate shear wall (SPSW) is commonly used in civil schemes because of its good deformability and stiffness. In this research, the numerical analysis of steel plate shear wall (SPSW) with unstiffened infill steel plate is conducted. This paper explains the effect of thickness variation of infill steel plate on behavior of steel plate. In this status, several samples are designed and checked by rigid frame and actuator. The experimental samples is joined to a rigid frame. 3 numerical specimens consist of steel plate shear wall with different thickness $(1.5,3,4.5) \mathrm{mm}$ formed by finite element code which is advanced by the Amirkabir university. To confirm the model, numerical results were discussed with a valid experiment which explain suitable agreement. Numerical model tested under cyclic loading with frequency of $1 / 60 \mathrm{~Hz}$. Results show that the increase of infill steel plate thickness enhance stiffness and ductility ratio of model. And so, would decrease energy absorption in comparison with the reference model.
\end{abstract}

Keywords: Steel shear wall, Buckling, High strength.

Paper History: Received: (19/9/2016), Accepted: (20/12/2016)

\section{Introduction}

Steel plate shear wall(SPSW) is the first type of shear wall discover in 1960. This type of shear wall extensively used in civil projects ,because it uses an effective resisting system against lateral loads. Steel shear wall is widely used in north America and japan, where it is developed by several form to resist all type of lateral load in different area. Steel shear wall consist of infill steel plate, boundary beam and columns. For steel infill panels, one process apply heavily stiffened steel plate shear walls to secure that the wall panel check its full plastic strength before to out of plane buckling. Thus stiffened, the wall panels can keep large lateral forces and disperse earthquake generate energy. Steel shear wall have many specifications include low cost, small thickness, lightweight and very good lateral load resisting system, so it is used in seismic zones. There are many experimental and numerical studies on behavior of steel shear wall under static or cycle load. These studies includes large scale or small scale of steel shear wall with different designs. Studies have been reported in Canada (Timler and Kulak 1983; Tromposch and Kulak 1987; Driver et al. 1997), the United States (Caccese et al. 1993; Elgaaly and Liu 1997), Japan (Yamada 1992), and England (Roberts and SabouriGhomi 1991). Xue and Lu (1994) stated on an wide analytical research of a hypothetical 12 story steel building frame including infill panels with different attachment specifics. All research studied the behavior of steel plates through the full range of loading, from prebucking to post buckling and from elastic to plastic stages. The consequences acquired from the papers unanimously support the rationale of utilizing tension field action, post buckling strength, and constant energy dissipation capacity of the steel infill panels in delineation the primary lateral load resisting system for structures. Although SPSW are consider easy system but need to more analytical studies. So in this paper by using finite element method three specimens of SPSW were modeled with unstiffened infill steel plate.

\section{Research Justification}

In the past, there were a lot of studies about the SPSW but most of these studies mainly focused on the behavior of SPSW under static load. While this study regard to study behavior of the SPSW under cyclic load and study influence of infill steel plate on SPSW . At recent years, the use of SPSW increased significantly in seismic region building. This drove the researchers to examine the properties of SPSW under cyclic load.

\section{Numerical modeling}

The numerical study of model made by finite element analysis by using (ANSYS) program, version (13.0). The best size for the FE. Meshes were chosen and the steel plate and shear wall frame were formed. Column and beam meshes were prepared so that they synchronize with the boundaries of the steel plate meshes so mutual joint would be 
modeled. Since the convergence criteria have been considered for force and displacement in all models. So the element choice to represent infill steel plate ,beam and columns were 3D shell181 with 6 degree of freedom. It is worth mentioning the infill steel plate connected to the steel frame by welding and the gravity load is not considered for them.

\section{Description Of Different Parts Of The Steel Shear Wall System For Its Performance}

Steel plate is a major element in steel shear wall. Preferably, this plate is chosen of steel with low yield point. For example St37 steel plate is preferred for high strength steel plate. Because St37 steel plate due to its low yield point is preferred to encourage yielding of steel plate. SPSW is a lateral force resisting system composed of a thin steel web-plate bounded by and attached to a surrounding portal frame. As shown in Figure 1 Comparing experimental with numerical models.

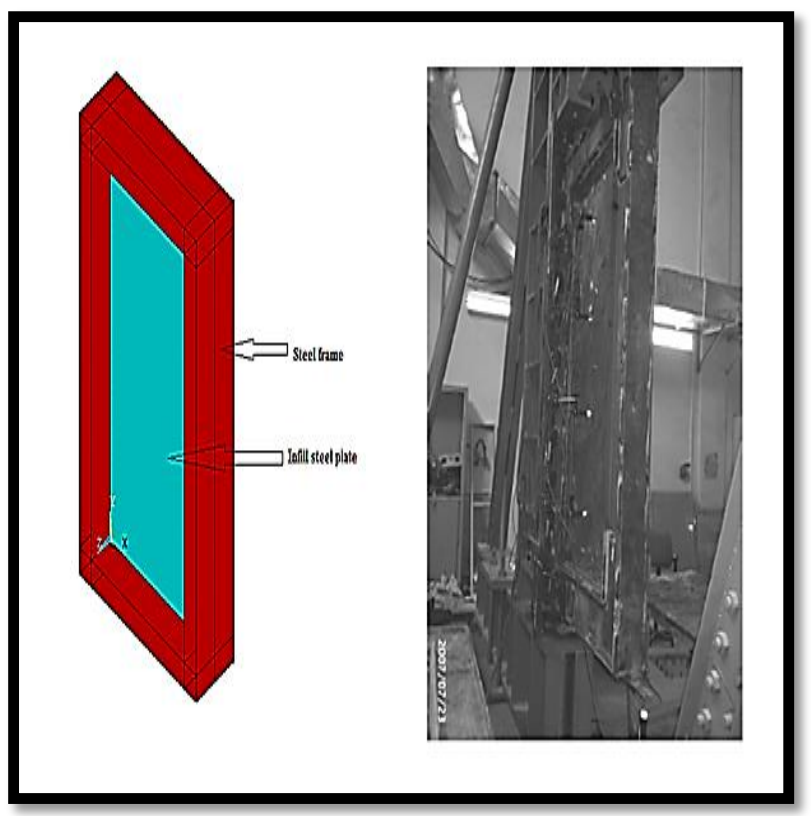

Figure 1: Comparing experimental with numerical models

\section{Model Properties And Investigation Parameter}

All the models in this study has the following properties:

- Steel plate yield is $240 \mathrm{MPa}$.

- $\quad$ Poison's Coefficient $=0.3$

- $\quad$ Elastic Modules $=206$ kN/mm

\section{Geometrical Properties Of Models}

The length of frame span that is center distance to center of both sides column is $2000 \mathrm{~mm}$ and height is also frame $1000 \mathrm{~mm}$ which is center distance to center of top and bottom beams. Columns and beams sections were also double IPE2000 .Steel plate inscribed inside the boundary beams and columns, is $1776 * 776$ long and $1776^{*} 1776 \mathrm{~mm}$ wide, and the thickness of these plates are also considered (1.5, 3 and 4.5)mm as shown in Figure 2.

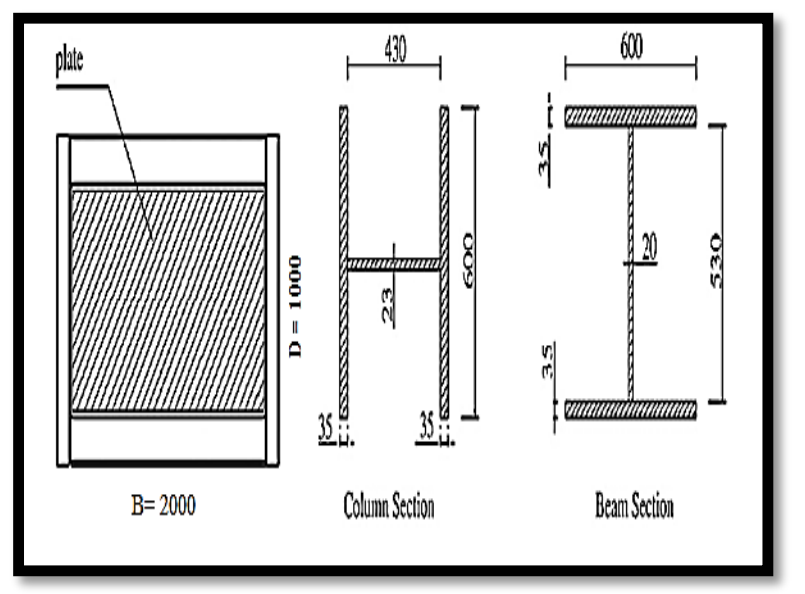

Figure 2: Specimen dimensions

7.Modeling Theories

To analyze model, the following theories were considered:

- Models at their lower level fixed on all directions.

- The behavior of used steel such as steel plate, beams and columns considered bilinear.

- Meshing of models was also selected so that connecting the flange to web at columns and beams profile and steel plate to the boundary elements in specimens were rigid connections. Mesh dimensions was also maximum $40 * 40 \mathrm{~mm}$.

\section{Loading}

At loading the cyclic loading the rate of frequency is $1 / 60 \mathrm{HZ}$ and the rate of amplitude value of the force is $600 \mathrm{kN}$, as shown in Figure 3. 


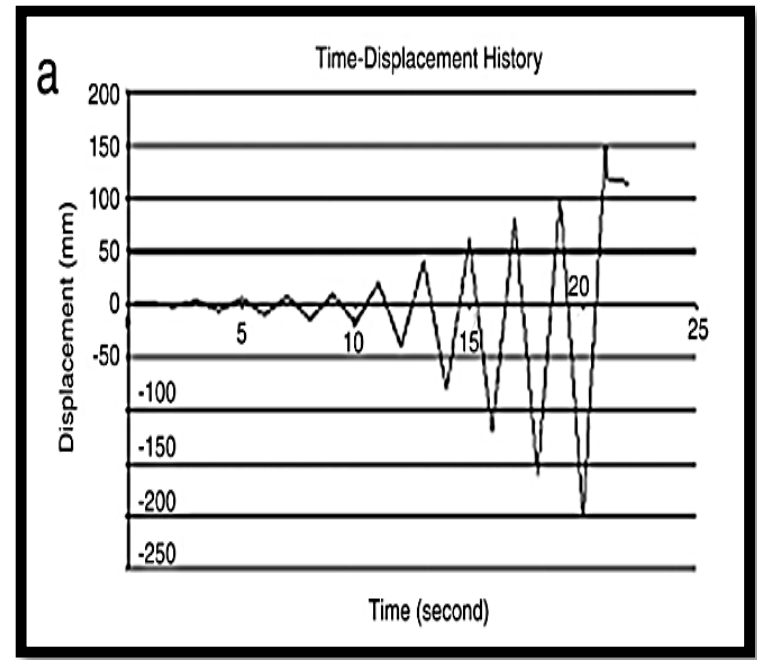

Figure 3: Cyclic Loading

9. Comparing The Result For The Numerical And Experimental Model

The nonlinear program ANSYS 13.0 used to construct validity of analyzed model of steel shear wall specimen $(1000 * 2000 \mathrm{~mm})$ on which the thickness of infill steel plate is 3 $\mathrm{mm}$, and height overall ratio to the span is $1 / 2$. Applied under cyclic loading and its deformation-load diagram plotted and compared to the analyzed results of similar numerical model Figure 4. Table 1 show the compering result between experimental and numerical analysis.

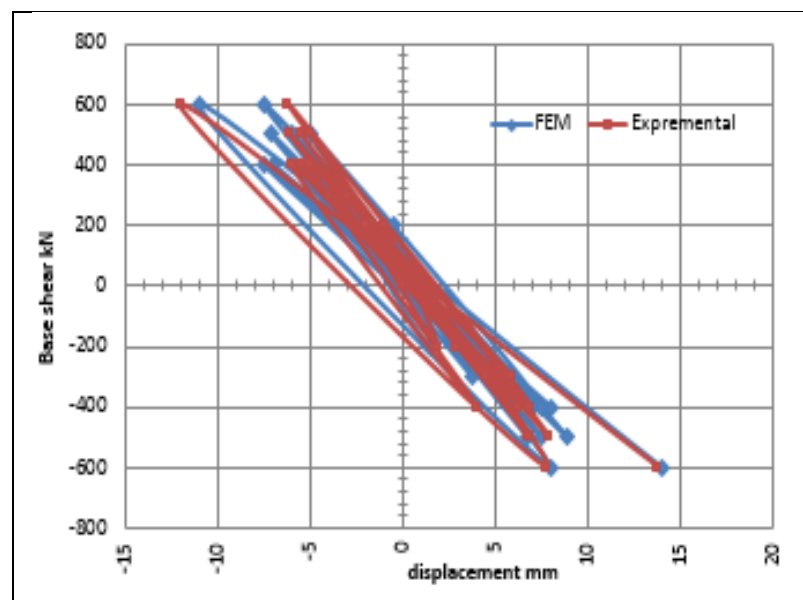

Figure 4: Comparing results of deformation-load in the numerical and experimental model for SSW
Table 1 comprising result between experimental and numerical analysis.

\begin{tabular}{|c|c|c|c|c|c|c|c|}
\hline \multirow[t]{2}{*}{ Case } & \multirow[t]{2}{*}{ Description } & \multicolumn{2}{|c|}{$\begin{array}{c}\text { Max, stress in } \\
\text { steel plate } \\
\left(\mathrm{AP}_{\mathrm{P}}\right)\end{array}$} & \multicolumn{2}{|c|}{$\begin{array}{l}\text { Min, \&.Max, off- } \\
\text { plane } \\
\text { deflection(mm) }\end{array}$} & \multicolumn{2}{|c|}{\begin{tabular}{|c} 
Max, in-plane \\
defflection \\
$(\mathrm{mm})$
\end{tabular}} \\
\hline & & Actual & Angys & Actual & Ansys & Actual & Ansyz \\
\hline 1 & SPSW(S-1.15) & - & 359 & - & 7.27 & - & 14.4 \\
\hline 2 & SPSW (S.3) & 340 & 328 & 8.2 & 6.5 & 14.2 & 14 \\
\hline 3 & SPSW(S.4.5) & - & 117 & - & 3.31 & - & 3.32 \\
\hline
\end{tabular}

\section{Software Output Results In Cyclic Loading}

At the last cyclic loading step, at step 41 the results of ANSYS output presented in Figure 5 to see out-of plane deflection of steel in numerical specimens.

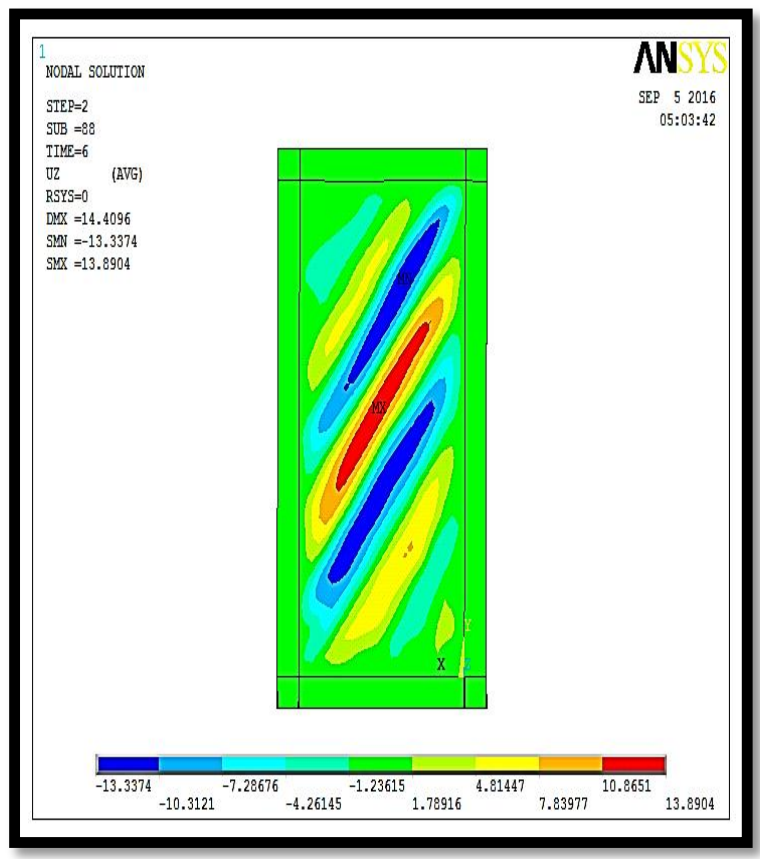

Figure 5: Out-of plane deflection of steel shear wall (SPSW)

\section{Comparing The Results Of Numerical} Models Analysis

Shear force-story drift curves are utilized to calculate the effect of the infill steel plate thickness to the behavior of SPSW. Variation thickness of infill steel plate, increase and decrease by $(1.5 \%)$ ratio to show the effect of these ratios on stiffness, ductility and energy absorption. It worth mentioning that the thickness of infill steel plate has direct effect on cycle behavior of steel shear wall, so increases the the thickness up to specific value can enhance stiffness, ductility and energy dissipation. Figure 6, 7\&8 show the numerical result of all model. 


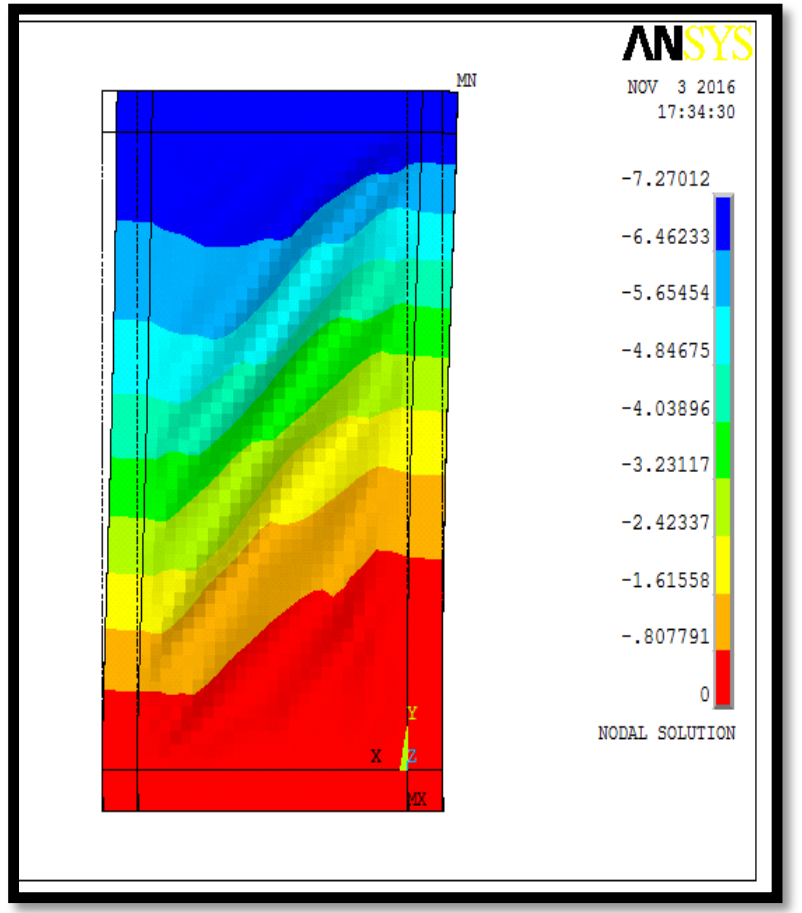

Figure 6: out off plane deflection of SPSW for 1.5 $\mathrm{mm}$ thickness of infill steel plate

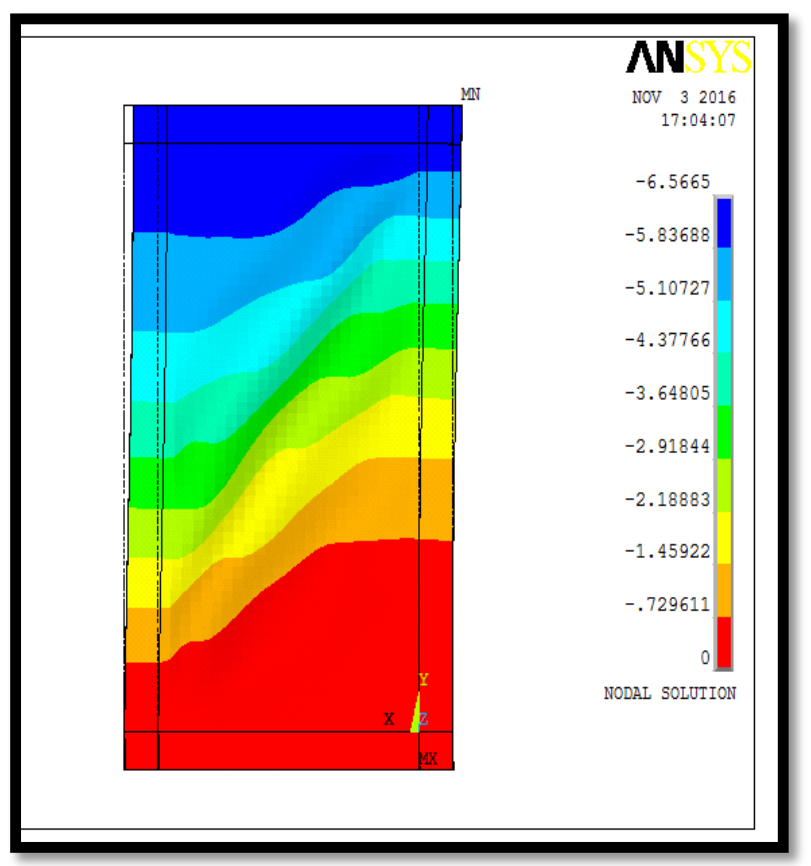

Figure 7: out off plane deflection of SPSW for $3 \mathrm{~mm}$ thickness of infill steel plate

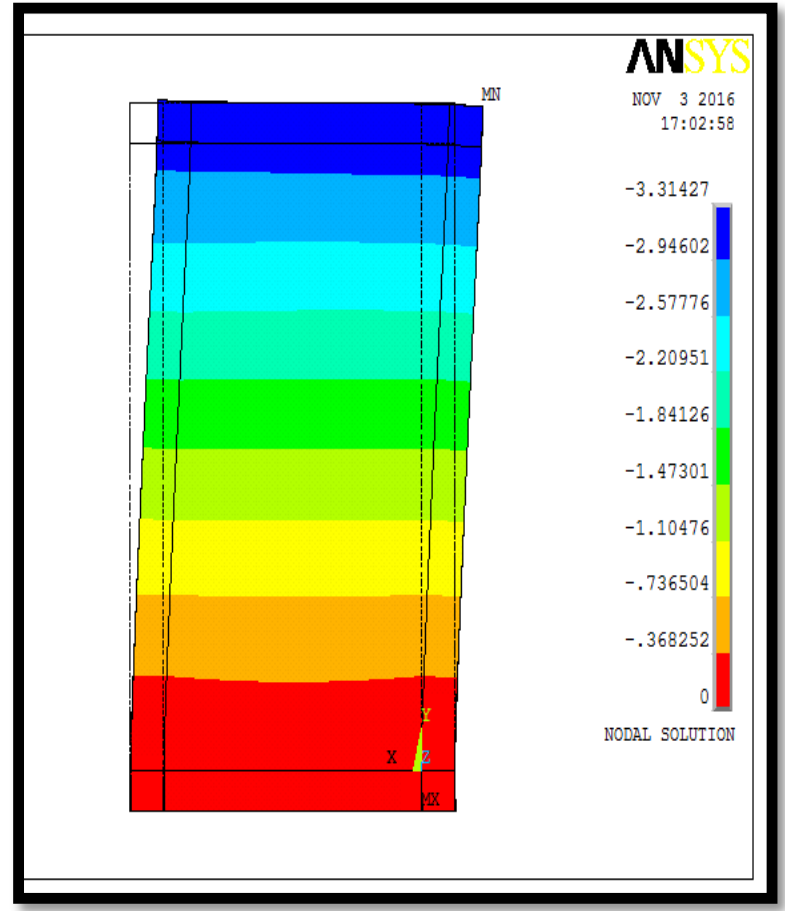

Figure 8: out off plane deflection of SPSW for $3 \mathrm{~mm}$ thickness of infill steel plate

\subsection{Initial Elastic Stiffness}

Stiffness is the ratio of load vs. deformation and can be used to describe either the elastic or plastic (after yield) range. When we show the load deflection curve, we concluded that the stiffness refer to the slop of the curve at any point along the curve. Table 2 presents the initial elastic stiffness $(\mathrm{Ke})$ and ratios of the initial elastic stiffness of SPSW to CSPSW (Kec/Kes). It can be rationally concluded that the SPSW with $4.5 \mathrm{~mm}$ thickness provide higher initial stiffness in rapprochement with the reference SPSW. Rising the infill steel plate thickness improves the initial lateral stiffness. The rising are roughly $49 \%$ for SPSW(S-4.5) in other meaning thickness of infill steel plate increase by $1.5 \%$ ratio, as the infill steel plate thickness change from $3 \mathrm{~mm}$ to $4.5 \mathrm{~mm}$. The main reason for increase stiffness when increase thickness of infill steel plate, is that resistance of SPSW to deflection increased and it is effect on the ability of shear wall to resist lateral load. Also it can be conduct that SPSW with $1.5 \mathrm{~mm}$ thickness give decrease in value of initial stiffness in rapprochement with the reference SPSW. The decrease are roughly $12 \%$ for $\operatorname{SPSW}(\mathrm{S}-1.5)$ in other meaning thickness of infill steel plate decrease by $1.5 \%$ ratio, as the infill steel plate thickness change from $3 \mathrm{~mm}$ to $1.5 \mathrm{~mm}$. 
Table 2 Initial elastic stiffness of SPSW with different infill steel plate thicknesses.

\begin{tabular}{|c|c|c|c|c|}
\hline $\begin{array}{c}\text { Model } \\
\text { (specimen) }\end{array}$ & Load (kN) & $\begin{array}{c}\text { Lateral } \\
\text { dis. }(\mathrm{mm})\end{array}$ & $\begin{array}{c}K_{t}=F / D \\
(\mathbf{k N / m m})\end{array}$ & $K_{t} / K$ \\
\hline SPSW(S-1.5) & 600 & 7.27 & 82.53 & 0.89 \\
\hline SPSW (S-3) & 600 & 6.5 & 92.31 & - \\
\hline SPSW(S-4.5) & 600 & 3.31 & 181.27 & 1.96 \\
\hline
\end{tabular}

\subsection{Ductility Ratios}

Ductility refer to the elongation that a material can undergo after it has yielded or exceeded it elastic range. When we show the load deflection curve, we concluded that the ductility refer to the length of curve after the yield point to failure. SPSW with different thickness of infill steel plate have different ductility ratios. Table 3 depicts the computed ductility of finite element models and the ductility ratio of SPSW(S-1.5) and SPSW(S4.5) to $\operatorname{SPSW}(\mathrm{S}-3)$. The ductility ratio is calculated as the proportion of the maximum displacement to the yield displacement $\left(\mu=\delta_{\max } / \delta_{y}\right)$. The yield point $\left(\delta_{y}\right)$ is computed throughout the concept of equal plastic energy, so that the area surrounded by the idealized elastic plastic curve is equivalent to that of the actual pushover curve, as shown in Figure 9. In accordance to the Table 3 ductility ratio of SPSW(S-4.5) are enhanced, as the thickness of steel plate raises. The ductility ratio of $\operatorname{SPSW}(\mathrm{S}-4.5)$ is extremely greater in rapprochement to its corresponding $\operatorname{SPSW}(\mathrm{S}-$ $3)$. It can be obviously noticed that rising thickness of steel plate from $(3 \mathrm{~mm})$ to $(4.5$ $\mathrm{mm}$ ) enhances the ductility ratios of SPSW with ratio $40 \%$. The main reason for increase ductility when increase thickness of infill steel plate, is that moment inertia increased and it is effect on the ability of shear wall to resist lateral load. Also when the thickness of steel plate decrease by $(1.5) \%$, it can be seen that the ductility ratio decrease by $11 \%$.

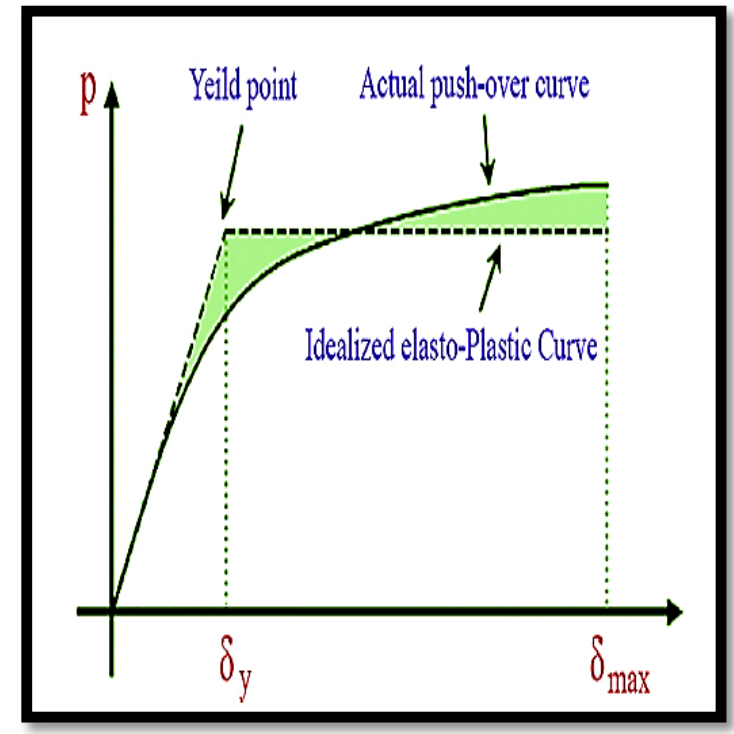

Figure 9: Definition of a yield point

Table 3 Ductility ratio of CSPWS with different thickness of infill steel plate.

\begin{tabular}{|c|c|c|c|c|}
\hline $\begin{array}{c}\text { Model } \\
\text { (specimen) }\end{array}$ & $\begin{array}{c}\delta_{\max } \\
(\mathrm{mm})\end{array}$ & $\begin{array}{c}\delta_{y} \\
(\mathrm{~mm})\end{array}$ & $\mu=\delta_{\max } / \delta_{y}$ & $\mu_{e} / \mu$ \\
\hline SPSIW(S-1.5) & 7.27 & 3.5 & 2.07 & 0.89 \\
\hline SPSW (S-3) & 6.5 & 2.8 & 2.32 & - \\
\hline SPSW(S-4.5) & 3.31 & 0.85 & 3.88 & 1.67 \\
\hline
\end{tabular}

\section{1-3 Energy Absorption}

Energy absorption capability is an important indicator of model's tolerance to loading. Models with high energy absorption capability are usually found to have high resistance to impact and crash loading, and hence are useful for high performance structures. The absorbed energy by a shear wall in a half-cycle can be rationally assumed as the area under(shear load-displacement), from which the area of recoverable elastic is not subtracted. It is presumed that the unloading and the elastic moduli are approximately the same. depicts the computed absorbed energy and the percentage of enhancement in energy absorption in SPSW(S-3) as contrast to their corresponding to $\operatorname{SPSW}(\mathrm{S}-1.5)$ and $\operatorname{SPSW}(\mathrm{S}-4.5)$. In accordance with Table 4 the energy absorption of $\operatorname{SPSW}(\mathrm{S}-1.5)$ is improved, as the thickness of infill steel plate decreases. The maximum energy absorption of the system is acquired. It can be distinctly viewed that energy absorption of $\operatorname{SPSW}(\mathrm{S}-1.5)$ is that escalates roughly $(11 \%)$ as rapprochement to their corresponding SPSW(S-3). Also it can be conduct that when the thickness of infill steel plate increase by $(1.5) \%$, the energy absorption decrease by $96 \%$. 
Table 4 Energy absorption of SPSW with different thickness of infill steel plate.

\begin{tabular}{|c|c|c|}
\hline $\begin{array}{c}\text { Model } \\
\text { (specimen) }\end{array}$ & $\begin{array}{c}\text { Energy absorption } \\
\text { (KJ) }\end{array}$ & $\begin{array}{c}\text { Energy absorption } \\
\text { ratio\% }\end{array}$ \\
\hline SPST(S-1.5) & 1454 & 1.12 \\
\hline SPSIT(S-3) & 1300 & - \\
\hline SPST(S-4.5) & 662 & 0.51 \\
\hline
\end{tabular}

11.4 Discussion Of Change Thickness Of Infill Steel Plate On Behavior Of CSPW

It can be seen that the thickness of infill steel plate is considered an influential factor on the cyclical behavior of steel shear wall. It is worth mentioning When the thickness of infill steel plate is small, the SPSW shows outright hysteretic curve under cyclic loading, sense better energy absorption capacity. With the increase thickness of infill steel plate, the pinch effect of hysteretic curves becomes more heavy, and the stiffness increases slowly. The reason is that the out of plane deformation develops slowly with the increase of thickness of infill steel plate. All curves show no overturn trend illustrating that this component has good ductility behavior.

\section{Summary And Conclusion}

Variations in the thickness of infill steel plate at steel shear wall up to a specific value can increase ductility, stiffness. With respect to the analysis, ratio of enhance for stiffness and ductility obtained for steel shear wall as 1:3 scales equivalent $49 \%, 40 \%$ with respect to the thickness $4.5 \mathrm{~mm}$ of steel plate, at cyclic loading.

\section{References}

[1]. Ansys, I. ANSYS advanced analysis techniques guide. Ansys Help, 2007.

[2]. Caccese, V., Elgaaly, M., \& Chen, R. Experimental study of thin steel-plate shear walls under cyclic load. Journal of Structural Engineering, 119(2), (1993), 573-587

[3]. Driver, R. G., Kulak, G. L., Elwi, A. E., \& Kennedy, D. L. FE and simplified models of steel plate shear wall. Journal of Structural Engineering, 124(2), (1998), 121-130

[4]. Driver, R. G., Kulak, G. L., Kennedy, D. L., \& Elwi, A. E. Cyclic test of four-story steel plate shear wall. Journal of Structural Engineering, 124(2), (1998), 112-120.

[5]. Elgaaly, M., \& Liu, Y. Analysis of thinsteel-plate shear walls. Journal of Structural Engineering, 123(11), (1997), 1487-1496.

[6]. Roberts, T. M., \& Ghomi, S. S. Hysteretic characteristics of unstiffened plate shear panels. Thin-Walled Structures, 12(2), (1991),
145-162.

[7]. Timler, P. A., \& Kulak, G. L. Experimental study of steel plate shear wall, 1983.

[8]. Tromposch, E. W., \& Kulak, G. L. Cyclic and static behaviour of thin panel steel plate shear walls. Department of Civil Engineering, University of Alberta, 1987.

[9]. Xue, M., \& Lu, L. W. Interaction of infilled steel shear wall panels with surrounding frame members. Proceedings of the structural stability research council annual technical session, Bethlehem, PA, (1994), 339354.

[10]. Yamada, M. Steel panel encased RC composite shear walls. In Composite Construction in Steel and Concrete II, (1992), 899-912. ASCE. 